\title{
PENGGUNAAN MINI POSTER TERHADAP PERILAKU MEROKOK PADA REMAJA DI DESA KARANG ANYAR KECAMATAN KEDUNGBANTENG KABUPATEN TEGAL
}

\author{
Masturoh $^{1}$, Siswati $^{2}$ \\ Email: ${ }^{1}$ masturoh87@gmail.com, 2 jinanalmira@gmail.com \\ ${ }^{(1,2)}$ Program Studi D III Kebidanan, Stikes Bhakti Mandala Husada Slawi, Jl. Cut Nyak Dien No. 16, Slawi, Kab. Tegal
}

\begin{abstract}
Abstrak
Indonesia merupakan negara dengan peringkat ketujuh tertinggi di dunia untuk jumlah produksi rokok dan sudah menempati posisi negara ke empat dengan jumlah perokok terbanyak di dunia. Selain itu proposi perokok laki-laki usia muda di Indonesia merupakan yang tertinggi di Asia. Bahkan perokok usia sekolah 15-19 tahun meningkat dua kali lipat dalam sepuluh tahun terakhir dan perokok laki-laki meningkat empat kali lipat selama 20 tahun terakhir. Perilaku merokok merupakan perilaku sebagian besar masyarakat, walaupun sudah mengetahui bahaya merokok. Metode penelitian ini menggunakan kuantitatif dengan pendekatan cross sectional. Subyek penelitian ini adalah remaja yang merokok di Desa Karanganyar Kecamatan Kedungbanteng Kabupaten Tegal sejumlah 30 orang pada bulan februari 2019. Analisis yang digunakan dalam penelitian ini adalah analisis bivariat dengan uji beda Wilcoxon. Hasil penelitian didapatkan bahwa tidak terdapat pengaruh yang bermakna penggunaan mini poster terhadap perilaku merokok pada remaja dengan nilai $p>0,05(0,83)$. Selain itu juga terdapat penurunan konsumsi rokok 1,73 kali lebih besar setelah penggun aan mini poster. Kesimpulan penelitian ini tidak terdapat pengaruh yang bermakna penggunaan mini poster terhadap perilaku merokok pada remaja. Saran bagi para perokok diharapkan agar menyadari bahaya merokok bagi kesehatan, dampaknya bukan hanya diri sendiri tetapi juga pada keluarga dan lingkungan.
\end{abstract}

\begin{abstract}
Indonesia is the seventh highest country in the world for the number of cigarette production and has occupied the position of the fourth country with the highest number of smokers in the world. In addition, the proportion of young male smokers in Indonesia is the highest in Asia. Even smokers aged 15-19 years have doubled in the last ten years and male smokers have quadrupled over the past 20 years. Smoking behavior is the behavior of most people, even though they already know the dangers of smoking. This research method uses quantitative with cross sectional approach. The subjects of this study were adolescents who smoked in Karanganyar Village, Kedungbanteng District, Tegal District, 30 people in February 2019. The analysis used in this study was bivariate analysis with a Wilcoxon different test. The results there was no significant effect on the use of mini posters on smoking behavior in adolescents with a value of $p>0.05(0.83)$. In there was also a decrease in cigarette consumption 1.73 times greater after using a mini poster. The conclusion of this study was that there was no significant effect on the use of mini posters on smoking behavior in adolescents. Suggestions for smokers are expected to be aware of the dangers of smoking for health, the impact is not only on yourself but also on family and the environment.
\end{abstract}

Korespondensi :

Masturoh, StiKes Bhakti Mandala Husada Slawi, Jl. Cut Nyak Dien No. 16, Slwi, Kab. Tegal, 085227006863 , masturoh87@gmail.com

\section{Pendahuluan}

Merokok merupakan kegiatan yang menyebabkan ketergantungan yang sudah menjadi kegiatan yang sering dilakukan oleh masyarakat di Indonesia bahkan di dunia. Indonesia merupakan negara dengan peringkat ketujuh tertinggi di dunia untuk jumlah produksi rokok dan sudah menempati posisi negara ke empat dengan jumlah perokok terbanyak di dunia. Selain itu proposi perokok laki-laki usia muda di Indonesia merupakan yang tertinggi di Asia. Bahkan perokok usia sekolah 15-19 tahun meningkat dua kali lipat dalam sepuluh tahun 
terakhir dan perokok laki-laki meningkat empat kali lipat selama 20 tahun terakhir (Prabandari, 2018).

Berdasarkan perkembangan Survey Demografi Kesehatan Indonesia (SDKI) dari tahun 2002 sampai 2017 prevalensi merokok pada remaja umur 15-19 tahun mengalami penurunan dari 50\% pada tahun 2002 menjadi $43 \%$ pada tahun 2012. Namun mengalami peningkatan kembali menjadi 48\% pada SDKI tahun 2017 (SDKI, 2017). Sedangkan berdasarkan RISKESDAS 2018 prevalensi merokok penduduk dengan umur $>10$ tahun pada tingkat nasional mencapai $28 \%$, dan $45 \%$ prevalensi di provinsi Jawa Tengah (Kemenkes RI, 2018).

Rokok merupakan salah satu produk tembakau yang dimaksudkan untuk dibakar dan dihisap dan/atau dihirup asapnya, termasuk rokok kretek, rokok putih, cerutu atau bentuk lainnya yang dihasilkan dari tanaman nicotiana tabacum, nicotiana rustica, dan spesies lainnya atau sintetisnya yang asapnya mengandung nikotin dan tar, dengan atau tanpa bahan tambahan (PP no. 109, 2012)

Perilaku merokok merupakan perilaku sebagian besar masyarakat, walaupun sudah mengetahui bahaya merokok, yang terdapat pada iklan rokok. Hal yang lebih memprihatinkan bukan hanya orang dewasa yang merokok namun merambah pada usia remaja bahkan siswa sekolah (Ambarwati dkk, 2014).
Kebiasaan merokok, merupakan salah satu faktor risiko Penyakit Tidak Menular (PTM), untuk pengendalian PTM Indonesia telah memperkenalkan gerakan Masyarakat Sehat (GERMAS) yang salah satunya adalah pengendalian merokok. Ironinya pengendalian merokok belum menjadi awal GERMAS, meskipun rokok telah menjadi factor utama PTM di Indonesia. Salah satu kebijakan pemerintah untuk pengendalian rokok yaitu dengan Kawasan Tanpa Rokok, tapi belum sepenuhnya berjalan. Sehingga penyakit kecanduan rokok telah menjadi tantangan penggiat pelayanan kesehatan, terutama layanan promosi kesehatan untuk melakukan pengendalian rokok. (Prabandari, 2018).

Berdasarkan hasil penelitian Ikhsan (2013) menyimpulkan bahwa dengan Pendidikan kesehatan tentang bahaya rokok terbukti mengurangi konsumsi rokok pada remaja. Selain itu hasil penelitian Kasman (2017) menyimpulkan bahwa media leaflet lebih efektif dalam meningkatkan pengetahuan remaja tentang bahaya merokok dibandingkan video, juga menunjukan peningkatan rata-rata pengetahuan.

\section{Metode Penelitian}

Metode penelitian ini menggunakan penelitian Kuantitatif dengan pendekatan cross sectional, dengan jenis penelitian eksperimen, dengan rancangan penelitian pretest and posttes without control group BHAMADA, JITK, Vol. 10, No. 1, April 2019 
design. Populasi penelitian ini adalah remaja yang merokok di Desa Karanganyar

Penelitian ini bersumber dari data primer dan sekunder yang bersumber dari hasil Survey Mawas Diri (SMD). Variabel independen dalam penelitian ini yaitu, penggunaan mini poster sedangkan variabel dependen adalah perilaku merokok pada remaja. Penelitian dilakukan dengan memberi kuesioner pada responden, kemudian responden diberi mini poster tentang bahaya merokok yang berupa gantungan kunci. Setelah satu minggu responden diberi kuesioner yang sama untuk di isi. Metode analisis yang digunakan adalah analisis dengan menggunakan sistem komputerisasi SPSS dengan uji statistic Wilcoxon. Karena data berdistribusi tidak
Kecamatan Kedungbanteng Kabupaten Tegal dengan jumlah sampel 30 orang.

normal (Riwidikdo, 2008). Uji statistic Wilcoxon digunakan untuk mengetahui perbedaan pengaruh antara penggunaan mini poster dengan perilaku merokok pada remaja yang disajikan dalam bentuk tabulasi.

\section{Hasil penelitian}

a. Analisa Univariat

Proporsi responden pada penelitian ini adalah umur 12 - 20 tahun. Mayoritas responden berumur 18 tahun ada 7 orang $(23,30 \%)$, umur 15 tahun ada 6 orang (20,00\%), umur 17 tahun ada 5 orang (16,70\%), umur 16 tahun ada 4 orang $(13,30 \%)$, umur $12,13,14$, dan 19 tahun masing-masing 2 orang $(6,67 \%)$.

Tabel 3.1 Proporsi Responden Berdasarkan Umur

\begin{tabular}{ccl}
\hline Umur (Tahun) & Frekuensi & $\%$ \\
\hline 12 & 2 & 6,6 \\
\hline 13 & 2 & 6,6 \\
\hline 14 & 2 & 6,6 \\
\hline 15 & 6 & 20,0 \\
\hline 16 & 4 & 13,3 \\
\hline 17 & 5 & 16,7 \\
\hline 18 & 7 & 23,3 \\
\hline 19 & 2 & 6,6 \\
\hline Total & 30 & 100 \\
\hline
\end{tabular}

Sumber : Data Primer

Berdasarkan tabel 3.1 pendidikan reponden mayoritas setara dengan SMK ada 23 orang $(76,67 \%)$, yang paling sedikit berpendidikan SD 1 orang (3,33\%), dan yang berpendidikan SMP ada 6 orang (20\%). Dari data tersebut sesuai dengan penelitian Rhido (2016) yang meytakan bahwa usia pemula perokok dimulai dari usia remaja muda. 
Tabel 3.2 Proporsi Responden Berdasarkan Pendidikan

\begin{tabular}{ccc}
\hline Pendidikan & Frekuensi & $\%$ \\
\hline SD & 1 & 3,3 \\
\hline SMP & 5 & 16,7 \\
\hline SMA/SMK & 24 & 80 \\
\hline Total & 30 & 100
\end{tabular}

Sumber : Data Primer

Berdasarkan tipe perokok, responden

ada 12 orang $(40,0 \%)$, sedangkan pada mayoritas perokok ringan dengan jumlah 18 orang $(60,0 \%)$ dan perokok sedang responden tidak ada perokok dengan tipe perokok berat.

Tabel 3.3 Proporsi Responden Berdasarkan Tipe Prokok Sebelum Penggunaan Poster

\begin{tabular}{ccc}
\hline Tipe Perokok & Frekuensi & $\%$ \\
\hline Ringan & 18 & 60,0 \\
\hline Sedang & 12 & 40,0 \\
\hline Berat & 0 & 0 \\
\hline Total & 30 & 100
\end{tabular}

\section{Sumber :Data Primer}

Setelah penggunaan mini poster terjadi penurunan konsumsi rokok, jika sebelum penggunaan mini poster mayoritas remaja adalah perokok ringan tetapi setelah penggunaan mini poster mayoritas remaja sudah tidak merokok.

Tabel 3.4 Proporsi Tipe Perokok Sesudah Penggunaan Mini Poster

\begin{tabular}{lcc}
\hline Tipe Perokok & Frekuensi & $\%$ \\
\hline Tidak Merokok & 15 & 50,0 \\
\hline Ringan & 9 & 30,0 \\
\hline Sedang & 6 & 20,0 \\
\hline Berat & 0 & 0 \\
\hline Total & 30 & 100 \\
\hline
\end{tabular}

Sumber : Data Primer

b. Analisa Bivariat

Analisis bivariat ini digunakan untuk mengetahui perbedaan hubungan atau pengaruh antara variabel dependen dan variabel independen.

Rencana penelitian ini menggunakan uji beda paired $\mathrm{t}$ test. Uji normalitas data yang digunakan adalah Shapiro-Wilk. Hasil uji normalitas data didapatkan nilai p 0,001 yang berarti bahwa data berdistribusi tidak normal. Sehingga yang digunakan non parametrik dengan uji Wilcoxon. Menurut Riwidikdo (2008) uji beda dengan data yang berdistribusi tidak normal maka menggunakan uji Wilcoxon. Berikut tabel hasil analisa data 
Tabel 3.5 Perbedaan Pengaruh Penggunaan Mini Poster Terhadap Perilaku Merokok Pada Remaja.

\begin{tabular}{l|lccc}
\hline \multicolumn{1}{c|}{ Data } & & $\mathrm{N}$ & $\mathrm{Z}$ & $\mathrm{p}$ \\
\hline Post_Poster - & Negative Ranks & 3 & $-1,73$ & 0,83 \\
\cline { 2 - 5 } Pre_Poster & Positive Ranks & 0 & & \\
\cline { 2 - 5 } & Ties & 27 & & \\
\cline { 2 - 5 } & Total & 30 & & \\
\hline
\end{tabular}

Berdasarkan table 3.4 menyatakan bahwa tidak terdapat pengaruh yang bermakna penggunaan mini poster terhadap perilaku merokok pada remaja dengan nilai $p>0,05 \quad(0,83)$. Tetapi hasil uji statistic menunjukan bahwa ada penurunan konsumsi rokok sebanyak 3 responden setelah penggunaan mini poster dan 27 responden tidak ada perubahan setelah penggunaan mini poster. Selain itu juga terdapat penurunan konsumsi rokok 1,73 kali lebih besar setelah penggun aan mini poster.

\section{Pembahasan}

a. Sebelum Penggunaan Mini Poster Terhadap Remaja Perokok

Pada responden tipe perokok mayoritas perokok ringan dengan jumlah 18 orang $(60,0 \%)$ dan perokok sedang ada 12 orang (40,0\%), sedangkan pada responden tidak ada perokok dengan tipe perokok berat. Hal tersebut terjadi karena perokok remaja baru pada fase mencoba-coba atau ikutikutan, sehingga dalam satu hari mengkonsumsi rokok 1-4 batang (perokok ringan). Hasil tersebut sesuai dengan Nurmiyanto dan Rachmani (2013) yang menyatakan bahwa ada beberapa alasan remaja merokok antara lain: coba-coba, ikut-ikutan, keingin tahuan, sekedar ingin merasakan, kesepian, agar terlihat gaya, meniru orang tua, iseng, menghilangkan ketegangan, agar tidak dikatakan banci, lambang kedewasaan, mencari inspirasi.

b. Sesudah Penggunaan Mini Poster.

Berdasarkan tabel 3.4 bahwa terjadi penurunan konsumsi rokok, jika sebelum penggunaan mini poster mayoritas remaja adalah perokok ringan tetapi setelah penggunaan mini poster mayoritas remaja sudah tidak merokok. Hal tersebut sesuai dengan penelitian Sukiman (2012) dalam Niska dan Gregorius (2013) menyatakan poster memiliki kelebihan, diantaranya adalah: dapat membantu menyampaikan materi dan membantu audience, menarik perhatian, mendorong peserta didik untuk lebih giat belajar, dapat dipasang atau ditempelkan dimana-mana, sehingga memberi kesempatan kepada audience untuk mempelajari dan mengingat kembali apa yang telah dipelajari, dapat menyarankan perubahan tingkah laku siswa yang melihatnya. 
c. Perbedaan Pengaruh Mini Poster Terhadap Perilaku Merokok Pada Remaja. Menurut Georgius (2013) poster adalah ilustrasi gambar yang disederhanakan, yang memberi tekanan pada satu atau dua ide pokok bertujuan agar dapat menarik perhatian, dapat dimengerti, diingat, membujuk, memotivasi dan memperingatkan pada peristiwa atau suatu hal tertentu.

Berdasarkan tabel 3.5 menyatakan bahwa tidak terdapat pengaruh yang bermakna penggunaan mini poster terhadap perilaku merokok pada remaja dengan nilai $p>0,05$ $(0,83)$. Tetapi hasil uji statistic menunjukan bahwa ada penurunan konsumsi rokok sebanyak 3 responden setelah penggunaan mini poster dan 27 responden tidak ada perubahan setelah penggunaan mini poster. Selain itu juga terdapat penurunan konsumsi rokok 1,73 kali lebih besar setelah penggunaan mini poster. Menurut alamsyah (2007) dan rachmat (2013) dalam Ridha (2016) Dalam perilaku merokok, banyak faktor lain yang mempengaruhi seseorang untuk mulai merokok khususnya para remaja seperti, pengaruh orang tua, pengaruh teman sebaya, dan pengaruh iklan. Selain itu Menurut Notoatmojo (2010) butuh waktu untuk merubah suatu perilaku seseorang, seperti perilaku merokok yang butuh waktu untuk berhenti merokok. Hal tersebut didukung oleh pendapat
Leventhal \& Clearly (dalam Cahyani, 1995) yang dikutip kembali oleh Komasari (2000), ada empat tahap dalam perilaku merokok sehingga menjadi perokok, yaitu tahap preparatory, tahap initiation, tahap becoming a smoker, dan tahap maintenance of smoking. Hasil penelitian ini sejalan dengan hasil penelitian Hajjah (2016) yang menyatakan bahwa keberadaan poster sepertinya kurang efektif, karena semua para perokok aktif tidak mempercayai kebenaran posterposter peringatan bahaya merokok tersebut. Dari semua subjek penelitian tidak terlalu memperhatikan dan memaknai keberadaan poster-poster peringatan tersebut, tidak memperdulikan hingga mengabaikan pesan-pesan peringatan yang ada di kemasan rokok yaitu tentang bahaya merokok. Dan terbukti poster-poster peringatan tersebut tidak mengurangi atau menghilangkan kebiasaan merokok karena semua subjek penelitian para perokok aktif ini lebih mementingkan kepuasan yang didapat dari rokok. Namun hasil penelitian ini tidak sejalan dengan hasil penelitian arwin (2017) yang menyatakan bahwa poster menunjukkan adanya pengaruh terhadap pencegahan anemia terhadap perilaku dan kadar $\mathrm{Hb}$ ibu hamil di wilayah kerja Puskesmas Baki Sukoharjo. Sedangkan menurut Maga dan Yanti (2015) menunjukkan bahwa penyuluhan 
kesehatan dengan media poster dapat meningkatkan pengetahuan dan sikap remaja tentang bahaya rokok di SMA Negeri 2 Rantau Selatan. Berdasarkan media yang digunakan penelitian Jalanti (2018) menyatakan bahwa gantungan kunci tentang bahaya merokok memberikan pengaruh yang signifikan terhadap pengetahuan responden.

\section{Kesimpulan}

a. Proporsi responden pada penelitian ini adalah umur 12 - 20 tahun. Mayoritas responden berumur 18 tahun ada 7 orang (23,30\%), umur 15 tahun ada 6 orang (20,00\%), umur 17 tahun ada 5 orang (16,70\%), umur 16 tahun ada 4 orang $(13,30 \%)$, umur $12,13,14$, dan 19 tahun masing-masing 2 orang $(6,67 \%)$.

b. Pendidikan reponden mayoritas setara dengan SMK ada 23 orang (76,67\%), yang paling sedikit berpendidikan SD 1 orang $(3,33 \%)$, dan yang berpendidikan SMP ada 6 orang $(20 \%)$.

c. Tidak terdapat pengaruh yang bermakna penggunaan mini poster terhadap perilaku merokok pada remaja dengan nilai $p>0,05$ $(0,83)$. Tetapi hasil uji statistic menunjukan bahwa ada penurunan konsumsi rokok sebanyak 3 responden setelah penggunaan mini poster dan 27 responden tidak ada perubahan setelah penggunaan mini poster. Selain itu juga terdapat penurunan konsumsi rokok 1,73 kali lebih besar setelah penggun aan mini poster. Saran

Saran bagi para perokok diharapkan agar menyadari bahaya merokok bagi kesehatan, dampaknya bukan hanya diri sendiri tetapi juga pada keluarga dan lingkungan.

\section{Referensi}

Ambarwati, Khoiratul, Kurniawati, Darojah. 2014. Media Leaflet, Video Dan Pengetahuan Siswa Sd Tentang Bahaya Merokok (Studi pada Siswa SDN 78 Sabrang Lor Mojosongo Surakarta). Jurnal Kesehatan Masyarakat. No. 10. Volume 1.7-13

Arwin Arminati. 2017. Pengaruh Poster Pencegahan Anemia Terhadap Perilaku Dan Kadar Hb Ibu Hamil Di Wilayah Kerja Puskesmas Baki Sukoharjo. Fakultas Ilmu Kesehatan. Universitas Muhammadiyah Surakarta

Hajjah Nur. 2016. Perilaku Sosial Para Perokok Aktif Dan Respon Terhadap Poster Peringatan Bahaya Merokok Pada Kemasan Rokok. Jurnal Jom FISIP UGM. Vol 3. 1. 1-15

Ikhsan Henridha, dkk. 2013. Pengaruh Pendidikan Kesehatan Bahaya Merokok Terhadap Perilaku Mengurangi Konsumsi Rokok Pada Remaja

Jalanti SP. 2018. Pengaruh Media Promosi Gantungan Kunci Terhadap Perubahan Pengetahuan Bahaya Merokok Pada Siswa Smp Negeri 27 Samarinda. Program Studi Kesehatan Masyarakat Fakultas Kesehatan Dan Farmasi Universitas Muhammadiyah Kalimantan Timur

Kasman, Noorhidayah, Persada. 2017. Studi Eksperimen Penggunaan Media Leaflet Dan Video Bahaya Merokok Pada 
Remaja. Jurnal Publikasi Kesehatan Masyarakat Indonesia. No. 2. Volume 4. 57-61

Kemenkes RI. 2018. Hasil Utama Riskesdas. Jakarta : Badan Penelitian dan Pengembangan Kesehatan

Maga Sari S dan Yanti. 2015. Pengaruh media poster dan media leaflet terhadap pengetahuan dan sikap siswa di SMA Negeri 2 Rantau Selatan Kabupaten Labuhan Batu. Ilmu Kesehatan Masyarakat. Universitas Sumatra Utara

Niska B dan Gregorius J. 2013. Penggunaan Media Poster Untuk Peningkatan Hasil Belajar Siswa Pada Pelajaran Pendidikan Kewarganegaraan Di Sekolah Dasar. Jurnal PGSD. No. 1. Volume 2. 1-12

Notoatmodjo, S.2010. Ilmu Perilaku Kesehatan.Jakarta: Rineka Cipta

Nurmiyanto A dan Rahmani D. 2013. Sosialisasi Bahaya Rokok Guna
Meningkatkan Kesadaran Masyrarakat Akan Besarnya Dampak Buruk Rokok Bagi Kesehatan. Jurnal Inovasi dan kewirausahaan. No. 3. Volume 2. 224232

Pabandari, Yayi. 2018. Perilaku Merokok dan Tantangan Promosi Kesehatan (Pengukuhan Guru Besar). Yogyakarta : Fakultas Kedokteran Universitas Gajah Mada

Peraturan Pemerintah RI no. 109. 2012. Pengamanan Bahan Yang Mengandung Zat Adiktif Berupa Produk Tembakau Bagi Kesehatan. Jakarta

Riha A dan Hernawan AD. 2016. Efektifitas Booklet Berbahasa Daerah Pada Perilaku Merokok. Remaja. Jurnal LINK Poltekkes Semarang. No. 12. Volume 2. 13-19

Riwidikdo. 2008. Satistik Penelitian Kesehatan. Yogyakarta : Mitra Cendekia Press 